\title{
HIV Genetic Diversity in Cameroon: Possible Public Health Importance
}

\author{
CLEMENT B. NDONGMO, ${ }^{1,6}$ DANUTA PIENIAZEK, ${ }^{1}$ MONA HOLBERG-PETERSEN, ${ }^{2}$ \\ CAROL HOLM-HANSEN,${ }^{3}$ LEOPOLD ZEKENG,${ }^{4}$ STIG L. JEANSSON, ${ }^{2}$ LAZARE KAPTUE, ${ }^{5}$ \\ and MARCIA L. KALISH ${ }^{1}$
}

\begin{abstract}
To monitor the evolving molecular epidemiology and genetic diversity of HIV in a country where many distinct strains cocirculate, we performed genetic analyses on sequences from 75 HIV-1-infected Cameroonians: 74 were group $M$ and 1 was group $O$. Of the group $M$ sequences, 74 were classified into the following env gp41 subtypes or recombinant forms: CRF02 $(n=54)$, CRF09 $(n=2)$, CRF13 $(n=2)$, A $(n=5)$, CRF11 $(n=4)$, CRF06 $(n=1), \mathrm{G}(n=2), \mathrm{F} 2(n=2)$, and $\mathrm{E}(n=1$, CRF01), and 1 was a JG recombinant. Comparison of phylogenies for 70 matched gp41 and protease sequences showed inconsistent classifications for 18 (26\%) strains. Our data show that recombination is rampant in Cameroon with recombinant viruses continuing to recombine, adding to the complexity of circulating HIV strains. This expanding genetic diversity raises public health concerns for the ability of diagnostic assays to detect these unique HIV mosaic variants and for the development of broadly effective HIV vaccines.
\end{abstract}

$\mathbf{H}^{\mathrm{v}}$ IV-1 STRAINS FROM THE WEST-CENTRAL African country of Cameroon show remarkable genetic diversity. Cameroon is the only country where all three groups of HIV-1, M, N, and O cocirculate. ${ }^{1-3}$ Almost all the known HIV subtypes and many recombinants, including circulating recombinant forms (CRFs) CRF01, CRF02, CRF04, CRF06, CRF09, CRF11, CRF13, and numerous unique recombinants, have been described. ${ }^{4-8}$ Even recombination between $\mathrm{HIV}-1$ group $\mathrm{O}$ and $\mathrm{M}$ strains has been documented in Cameroon. ${ }^{9,10}$ It is well established that CRF02AG and recombinants containing portions of the CRF02 genome are the most prevalent strains in Cameroon. ${ }^{4-6,11}$ Continued genetic characterization of HIV-1 variants in this region, where multiple subtypes, CRFs, and unique recombinant forms (URFs) cocirculate, is important for global public health issues related to this diversity. For example, these complex recombinant viruses raise concern about whether any of these divergent strains might be missed by current diagnostic assays, as well as those assays currently under development.

Between September and November 1999, blood specimens were collected from 75 HIV-1-seropositive, antiretroviral drugnaive individuals, who routinely attended the tuberculosis (TB) and sexually transmitted infections (STIs) clinics in the seaport city of Douala and the capital city of Yaoundé, Cameroon. Blood specimens were screened for HIV using the rapid Abbott Determine HIV-1/2 assay (Abbott Laboratories, Abbott Park, IL) and two enzyme immunoassays, Genscreen HIV1/2 Version 2 (Pasteur Diagnostics, Paris, France) and AXSYM HIV1/2 gO (Abbott norge as, Oslo, Norway). Results from reactive specimens were confirmed by a Western blot test, HIV Blot 2.2 (Genelabs Diagnostics, Singapore). ${ }^{12}$ Peripheral blood mononuclear cells (PBMCs) were isolated from blood samples by Ficoll-Hypaque gradient density, pelleted, and stored at $-20^{\circ} \mathrm{C}$. All individuals provided informed consent, although samples used in this study were unlinked to patient identifiers.

Viral DNA was extracted from PBMCs using the GFX TM Genomic blood DNA purification kit (Amersham Pharmacia Biotech AB, Uppsala, Sweden) or the QIAamp DNA Mini Kit (QIAGEN Inc, Valencia, CA) according to the manufacturer's instructions. The env gp41 primary gp40F1-forward/gp41R1-reverse and nested gp46F2/gp48R2 polymerase chain reaction (PCR) primers, respectively, were used for amplification of a 445bp fragment. ${ }^{13}$ Nested PCR amplification of the entire protease (PR) gene with outside primers DP10-forward/DP11-reverse and inside primers DP16-forward/DP17-reverse was performed as pre-

\footnotetext{
${ }^{1}$ Centers for Disease Control and Prevention, Division of HIV/AIDS Prevention, Atlanta, Georgia 30333.

${ }^{2}$ Department of Microbiology, Ullevaal University Hospital, N-0407 Oslo, Norway.

${ }^{3}$ Norwegian Institute of Public Health, Oslo, Norway.

${ }^{4}$ Laboratoire de Sante Hygiene Mobile, Ministry of Health, Yaounde, Cameroon

${ }^{5}$ Department of Hematology and Immunology, Faculty of Medicine, Yaounde, Cameroon.

${ }^{6}$ Present address: Department of Microbiology and Immunology, University of Michigan Medical School, Ann Arbor, Michigan 48109-0620.
} 





Table 1. Sociodemographic and Genotypic Characteristics of HiV-1-Infected Patients from Cameroon

\begin{tabular}{|c|c|c|c|c|c|c|}
\hline \multirow[b]{2}{*}{ Sample ID } & \multirow[b]{2}{*}{ Clinic } & \multirow[b]{2}{*}{ City } & \multirow[b]{2}{*}{ Age } & \multirow[b]{2}{*}{ Sex } & \multicolumn{2}{|c|}{ HIV genetic subtype } \\
\hline & & & & & gp41 & $P R$ \\
\hline 99СМ001 & STI & Yde & 25 & $\mathrm{M}$ & CRF02_AG & CRF02_AG \\
\hline 99CM007 & STI & Yde & 28 & $\mathrm{~F}$ & CRF02_AG & CRF02_AG \\
\hline 99СМ014 & STI & Yde & 26 & $\mathrm{~F}$ & CRF02_AG & CRF02_AG \\
\hline 99СМ016 & STI & Yde & 28 & $\mathrm{~F}$ & CRF02_AG & CRF02_AG \\
\hline 99СМ026 & STI & Yde & 24 & $\mathrm{~F}$ & CRF06_px & $\mathrm{U}$ \\
\hline 99CM030 & TB & Yde & 27 & $\mathrm{~F}$ & CRF02_AG & CRF02_AG \\
\hline 99СМ031 & TB & Yde & 40 & $\mathrm{M}$ & CRF02_AG & $\mathrm{U}^{-}$ \\
\hline 99CM036 & STI & Yde & 28 & $\mathrm{M}$ & CRF02_AG & ND \\
\hline 99CM038 & STI & Yde & 28 & $\mathrm{M}$ & $\mathrm{G}^{-}$ & $\mathrm{G}$ \\
\hline 99СМ057 & $\mathrm{TB}$ & Yde & 40 & $\mathrm{~F}$ & CRF02_AG & CRF02_AG \\
\hline 99CM060 & TB & Yde & 35 & $\mathrm{M}$ & CRF02_AG & CRF02_AG \\
\hline 99CM068 & STI & Yde & 40 & $\mathrm{M}$ & CRF02_AG & CRF02_AG \\
\hline 99СМ069 & STI & Yde & 27 & $\mathrm{M}$ & CRF02_AG & CRF02_AG \\
\hline 99СМ072 & TB & Yde & 45 & $\mathrm{M}$ & CRF02_AG & $\mathrm{F} 2$ \\
\hline 99CM074 & STI & Yde & 20 & $\mathrm{~F}$ & CRF02_AG & CRF02_AG \\
\hline 99СМ076 & STI & Yde & 37 & $\mathrm{M}$ & CRF02_AG & CRF02_AG \\
\hline 99СМ079 & STI & Yde & 25 & $\mathrm{~F}$ & CRF11_cpx & CRF02_AG \\
\hline 99CM081 & STI & Yde & 27 & $\mathrm{M}$ & $\mathrm{O}^{-\mathrm{T}}$ & $\mathrm{O}$ \\
\hline 99CM082 & STI & Yde & 52 & $\mathrm{~F}$ & CRF02_AG & CRF02_AG \\
\hline 99CM090 & $\mathrm{TB}$ & Yde & 40 & $\mathrm{M}$ & CRF09_cpx & CRF02_AG \\
\hline 99CM091 & $\mathrm{TB}$ & Yde & 37 & $\mathrm{~F}$ & CRF11_cpx & CRF02_AG \\
\hline 99СМ092 & TB & Yde & 62 & $\mathrm{~F}$ & CRF02_AG & CRF02_AG \\
\hline 99CM107 & STI & Yde & 26 & $\mathrm{~F}$ & CRF02_AG & CRF02_AG \\
\hline 99CM109 & STI & Yde & 24 & $\mathrm{~F}$ & CRF02_AG & CRF02_AG \\
\hline 99CM113 & $\mathrm{TB}$ & Yde & 37 & $\mathrm{~F}$ & CRF02_AG & CRF02_AG \\
\hline 99CM115 & TB & Yde & 38 & $\mathrm{M}$ & CRF13_cpx & CRF02_AG \\
\hline 99CM124 & TB & Yde & 34 & M & CRF02_AG & CRF02_AG \\
\hline 99CM126 & STI & Yde & 23 & $\mathrm{~F}$ & CRF02_AG & CRF02_AG \\
\hline 99CM139 & STI & Yde & 30 & $\mathrm{M}$ & CRF02_AG & CRF02_AG \\
\hline 99CM143 & STI & Yde & 24 & $\mathrm{~F}$ & CRF02_AG & CRF02_AG \\
\hline 99CM148 & STI & Yde & 28 & $\mathrm{M}$ & $\mathrm{A}^{-}$ & ND \\
\hline 99CM149 & STI & Yde & 30 & $\mathrm{~F}$ & CRF02_AG & CRF02_AG \\
\hline 99CM171 & STI & Yde & 39 & $\mathrm{~F}$ & CRF02_AG & $\mathrm{ND}^{-}$ \\
\hline 99CM189 & STI & Yde & 32 & $\mathrm{M}$ & CRF02_AG & CRF02_AG \\
\hline 99CM191 & STI & Yde & 28 & $\mathrm{M}$ & CRF02_AG & CRF02_AG \\
\hline 99CM197 & STI & Yde & 32 & $\mathrm{M}$ & CRF02_AG & CRF02_AG \\
\hline 99CM203 & STI & Yde & 38 & $\mathrm{M}$ & CRF02_AG & CRF02_AG \\
\hline 99CM212 & STI & Yde & 33 & $\mathrm{M}$ & CRF13_cpx & CRF02_AG \\
\hline $99 \mathrm{CM} 213$ & STI & Yde & 33 & $\mathrm{M}$ & $\mathrm{F} 2$ & $\mathrm{~F} 2$ \\
\hline 99CM221 & TB & Yde & NA & $\mathrm{F}$ & CRF02_AG & CRF02_AG \\
\hline 99CM224 & STI & Yde & 27 & $\mathrm{~F}$ & CRF01_AE & CRF01_AE \\
\hline $99 \mathrm{CM} 225$ & STI & Yde & 24 & $\mathrm{~F}$ & CRF09_cpx & CRF02_AG \\
\hline 99CM227 & STI & Yde & 39 & $\mathrm{M}$ & CRF02_AG & CRF02_AG \\
\hline 99CM228 & STI & Yde & 60 & $\mathrm{M}$ & CRF02_AG & CRF02_AG \\
\hline 99CM229 & STI & Yde & 44 & $\mathrm{~F}$ & CRF02_AG & CRF02_AG \\
\hline 99CM247 & STI & Yde & 27 & $\mathrm{M}$ & CRF02_AG & CRF02_AG \\
\hline 99CM249 & STI & Yde & 29 & $\mathrm{~F}$ & CRF02_AG & CRF02_AG \\
\hline 99CM251 & STI & Yde & 22 & $\mathrm{~F}$ & CRF02_AG & CRF02_AG \\
\hline 99CM258 & STI & Yde & 30 & $\mathrm{~F}$ & CRF02_AG & CRF02_AG \\
\hline 99CM259 & STI & Yde & 53 & $\mathrm{~F}$ & A & CRF02_AG \\
\hline 99CM261 & STI & Yde & 21 & $\mathrm{M}$ & $\mathrm{F} 2$ & CRF11_cpx \\
\hline 99CM275 & $\mathrm{TB}$ & Dla & 35 & $\mathrm{M}$ & CRF02_AG & CRF02_AG \\
\hline $99 \mathrm{CM} 277$ & $\mathrm{~TB}$ & Dla & 48 & $\mathrm{~F}$ & CRF02_AG & CRF02_AG \\
\hline 99СМ279 & TB & Dla & 29 & $\mathrm{M}$ & $\mathrm{A}$ & CRF02_AG \\
\hline 99CM284 & TB & Dla & 38 & $\mathrm{M}$ & CRF02_AG & CRF02_AG \\
\hline 99СМ289 & TB & Dla & 36 & $\mathrm{~F}$ & CRF02_AG & CRF02_AG \\
\hline 99CM290 & TB & Dla & 31 & $\mathrm{M}$ & CRF02_AG & $\mathrm{U}^{-}$ \\
\hline 99CM311 & STI & Yde & 30 & $\mathrm{M}$ & CRF02_AG & CRF02_AG \\
\hline 99CM315 & STI & Yde & 39 & $\mathrm{~F}$ & A & CRF02_AG \\
\hline
\end{tabular}


Table 1. Sociodemographic and Genotypic Characteristics of HiV-1-Infected Patients from Cameroon (Cont'd)

\begin{tabular}{|c|c|c|c|c|c|c|}
\hline \multirow[b]{2}{*}{ Sample ID } & \multirow[b]{2}{*}{ Clinic } & \multirow[b]{2}{*}{ City } & \multirow[b]{2}{*}{ Age } & \multirow[b]{2}{*}{ Sex } & \multicolumn{2}{|c|}{ HIV genetic subtype } \\
\hline & & & & & gp41 & $P R$ \\
\hline 99CM316 & STI & Yde & 25 & $\mathrm{~F}$ & CRF02_AG & CRF02_AG \\
\hline 99CM318 & TB & Yde & 43 & M & CRF02_AG & CRF02_AG \\
\hline 99CM322 & STI & Yde & 33 & M & CRF02_AG & CRF02_AG \\
\hline 99CM324 & STI & Yde & 49 & M & CRF02_AG & CRF02_AG \\
\hline 99CM325 & STI & Yde & 25 & $\mathrm{~F}$ & CRF11_cpx & CRF11_cpx \\
\hline 99CM334 & STI & Yde & 39 & $\mathrm{~F}$ & CRF02_AG & $\mathrm{U}^{-}$ \\
\hline 99CM336 & STI & Yde & NA & M & $\mathrm{AG}_{\mathrm{CM} 53392}$ & $\mathrm{AG}_{\mathrm{CM} 53392}$ \\
\hline 99CM341 & STI & Yde & 20 & $\mathrm{~F}$ & $\mathrm{G} / \mathrm{J}$ & CRF11_cpx \\
\hline 99CM344 & STI & Yde & 32 & M & CRF02_AG & CRF02_AG \\
\hline 99CM360 & TB & Dla & 47 & $\mathrm{~F}$ & $\mathrm{G}$ & CRF02_AG \\
\hline 99CM362 & TB & Dla & 31 & M & CRF02_AG & CRF02_AG \\
\hline 99CM369 & TB & Dla & 33 & $\mathrm{~F}$ & CRF02_AG & CRF02_AG \\
\hline 99CM377 & TB & Dla & 43 & $\mathrm{~F}$ & CRF02_AG & CRF02_AG \\
\hline 99CM379 & TB & Dla & NA & NA & CRF02_AG & CRF02_AG \\
\hline 99CM384 & TB & Dla & 27 & $\mathrm{M}$ & CRF02_AG & $\mathrm{U}^{-}$ \\
\hline 99CM386 & TB & Dla & NA & NA & CRF11_cpx & ND \\
\hline
\end{tabular}

NA, not available; U, unclassified; ND, not done; Yde, Yaounde; Dla, Douala.

viously described. ${ }^{14}$ The PCR amplification was performed with the Platinum Taq DNA Polymerase High Fidelity PCR system according to the manufacturer's instructions (Life Technology, Bethesda, MD). After purification (Qiagen, Valencia, CA), PCR products were directly sequenced using both forward and reverse nested PCR primers for HIV-1 gp41 and PR gene regions and resolved on an automated DNA sequencer ABI model 377 (Applied Biosystems, Foster City, CA). The derived nucleotide sequences



FIG. 2. Sliding window bootscan analysis (window $160 \mathrm{bp}$; step $30 \mathrm{bp}$ ) of the Cameroonian unclassifiable env gp41 sequence 99CM341 showing the recombination between subtypes $\mathrm{G}$ and $\mathrm{J}$. The reference sequences were from the following subtypes: A (strain 92UG037), B (strain HXB2), C (strain ET2220), D (strain NDK), F1 (strain MP411), F2 (strain MP257), G (strain DRCBL), H (strain V19910, J (strain SE9173), K (strain EQTB11C), and potential L (strain 83CD03). were aligned using the Clustal W 1.83 multiple sequence alignment program included in the GeneStudio package (http://www. genestudio.com). Reference strains of groups $\mathrm{M}, \mathrm{N}$, and $\mathrm{O}$ were extracted from the Los Alamos databases (http://hiv-web.lanl.gov/ MAP/hivmap.html). Phylogenetic analysis was performed by the neighbor-joining method, with the nucleotide distance calculated by Kimura's two-parameter method included in the Phylip package version $3.5 \mathrm{c}$, with and without bootstrapping. ${ }^{15}$ An HIV-2 Rod sequence was used as an outgroup. To avoid the influence of other sequences on the bootstrap value, confirmations of subtype assignments were performed separately for each sequence. The stability of the tree topology was tested by pruning, which consists of removing one sequence from an alignment and rerunning the phylogenetic analysis. For recombination analysis of DNA sequences, SimPlot software was used (SimPlot for Windows; http://sray.med.som.jhmi.edu/RaySoft/SimPlot); this program calculates and plots the percentage identity of the query sequence with reference sequences from group $\mathrm{M}$ viruses, in a sliding-window manner along the alignment with optimal step size.

Phylogenetic analysis of 75 env gp41 sequences revealed that 74 clustered with HIV-1 group M (Fig. 1) while one clustered with group $\mathrm{O}$ (data not shown). The majority (85.0\%, 63 of 74) of group $\mathrm{M}$ sequences fell within the subtype A clade. Fifty-four (85.7\%) of the 63 subtype A sequences were further classified as CRF02, 2 as CRF13, 1 sequence clustered with a previously identified unique $\mathrm{AG}$ recombinant, $\mathrm{CM}_{53392}{ }^{8}$ (Fig. 1), and 2 sequences were found to be phylogenetically related to CRF09 (data not shown). Similarly, of seven sequences that clustered within the $\mathrm{G}$ clade five were further characterized: 4 grouped with CRF11-cpx reference sequences and 1 with CRF06-cpx. From the remaining 4 Cameroonian sequences, 2 were subsubtype F2, 1 was CRF01_AE, and 1 was unclassifiable (99CM341). Further pruning analysis revealed that the unclassifiable sequence clustered significantly ( $>80 \%$ bootstrap value) either with subtype $\mathrm{G}$ if subtype $\mathrm{J}$ was not included in phylogenetic analysis or with subtype $\mathrm{J}$ when subtype $\mathrm{G}$ sequences were absent (data not shown). These results suggested the presence of subtype $\mathrm{G}$ and $\mathrm{J}$ components in the 
99CM341 gp41 sequence. Sliding-window bootscan analysis of this sequence showed clear intersubtype recombination with elements of subtypes $\mathrm{G}$ at the $5^{\prime}$ portion and $\mathrm{J}$ at the $3^{\prime}$ end (Fig. 2).

To estimate the extent of recombination involving CRFs circulating in Cameroon in 1999, we compared the env gp41 phylogenies for 70 HIV-1 group $\mathrm{M}$ and 1 group $\mathrm{O}$ sequences with the subtype/CRF designations of their PR genes (Table 1). There was concordance between the two gene regions for the group $\mathrm{O}$ strain, as well as for $74 \%$ (52 of 70) of the group M strains as follows: CRF02 $(67.1 \%, n=47), \mathrm{CRF} 11(1.4 \%, n=1)$, CRF01 (1.4\%), cm53392 (1.4\%), G (1.4\%), and F2 (1.4\%). The remaining $18(26 \%)$ strains had discordant phylogenies with the following $10 \mathrm{gp} 41 / \mathrm{PR}$ mosaic structures: CRF02/unclass $(n=$ 4), A/CRF02 $(n=3), \mathrm{CRF} 13 / \mathrm{CRF} 02(n=2), \mathrm{CRF} 11 / \mathrm{CRF} 02$ $(n=2), \mathrm{CRF} 09 / \mathrm{CRF} 02(n=2), \mathrm{CRF} 02 / \mathrm{F} 2(n=1), \mathrm{G} / \mathrm{CRF} 02$ $(n=1), \mathrm{F} 2 / \mathrm{CRF} 11(n=1), \mathrm{CRF} 06 /$ unclass $(n=1)$, and intersubtype JG/CRF11 $(n=1)$. Overall, parallel analysis of the two gene regions, PR at $5^{\prime}$ and env gp41 at $3^{\prime}$-ends, revealed that only two $(2.9 \%)$ viruses carried potentially "pure" subtypes (G and F2). Although CRFs were predominant (76\%), almost 25\% were unique recombinants with discordant subtype/CRF designations between PR and env gene regions. Consistent with CRF02 being the most predominant strain in Cameroon, most of the recombinant strains contained a fragment of CRF02.

Overall, our data demonstrated a broad diversity among HIV sequences from Cameroon, including gp41 and/or PR sequences from subtypes, CRFs, and URFs. Recombination is ongoing between these forms of HIV, adding to the increasing diversity in this region, and raising public health concerns about the ability of serologic and nucleic acid-based diagnostic assays to detect these complex variants of HIV. Especially since most nucleic acid assays used by blood banks for detecting recent, "window period" infections have not been thoroughly evaluated on these unique, complex forms of HIV. Studies are ongoing to evaluate Cameroonian serum or plasma samples, with at least partial subtype characterization, against a large battery of assays being used to diagnose HIV infections. The increasing genetic diversity of Cameroonian strains also presents a serious challenge for designing and developing broadly effective HIV-1 vaccines. Finally, the extensive recombination between circulating strains in Cameroon and other countries where multiple subtypes, CRFs, and URFs cocirculate continues to create a dilemma for classification of these complex forms of HIV.

\section{SEQUENCE DATA}

The sequences presented in this report have been deposited in GenBank under accession numbers DQ394108-DQ394177 for protease sequences and AY707001-AY707074 for gp41.

\section{ACKNOWLEDGMENTS}

We thank Clement Zeh from CDC for his assistance and for sequencing the HIV-1 group O protease gene. We also wish to acknowledge the assistance of Gunilla Lövgården, Lise Andresen, and Marie Elisabeth Vad from the Microbiology laboratory, Ullevaal University Hospital, Oslo, Norway. The findings and conclusions in this report are those of the authors and do not necessarily represent the views of the Centers for Disease Control and Prevention.

\section{REFERENCES}

1. De Leys R, Vanderborght B, Vanden Haesevelde M, et al.: Isolation and partial characterization of an unusual human immunodeficiency retrovirus from two persons of west-central African origin. J Virol 1990;64(3):1207-1216.

2. Gurtler LG, Hauser PH, Eberle J, et al.: A new subtype of human immunodeficiency virus type 1 (MVP-5180) from Cameroon. $\underline{\mathrm{J} \text { Vi- }}$ rol 1994;68(3):1581-1585.

3. Simon F, Mauclere P, Roques $P$, et al.: Identification of a new human immunodeficiency virus type 1 distinct from group $M$ and group O. Nat Med 1998;4(9):1032-1037.

4. Burda ST, Konings FA, Williams CA, Anyangwe C, and Nyambi PN: HIV-1 CRF09_cpx circulates in the North West Province of Cameroon where CRF02_AG infections predominate and recombinant strains are common. AIDS Res Hum Retroviruses 2004; 20(12):1358-1363.

5. Ndembi N, Takehisa J, Zekeng L, et al.: Genetic diversity of HIV type 1 in rural eastern Cameroon. J Acquir Immune Defic Syndr 2004;37(5):1641-1650

6. Vergne L, Bourgeois A, Mpoudi-Ngole E, et al.: Biological and genetic characteristics of HIV infections in Cameroon reveals dual group $\mathrm{M}$ and $\mathrm{O}$ infections and a correlation between SI-inducing phenotype of the predominant CRF02_AG variant and disease stage. Virology 2003;310(2):254-266.

7. Wilbe $\mathrm{K}$, Casper $\mathrm{C}$, Albert J, and Leitner T: Identification of two CRF11-cpx genomes and two preliminary representatives of a new circulating recombinant form (CRF13-cpx) of HIV type 1 in Cameroon. AIDS Res Hum Retroviruses 2002;18(12):849-856.

8. Carr JK, Torimiro JN, Wolfe ND, et al:: The AG recombinant IbNG and novel strains of group M HIV-1 are common in Cameroon. Virology 2001;286(1):168-181.

9. Takehisa J, Zekeng L, Ido E, et al.: Human immunodeficiency virus type 1 intergroup (M/O) recombination in Cameroon. J Virol 1999;73(8):6810-6820.

10. Peeters M, Liegeois F, Torimiro N, et al.: Characterization of a highly replicative intergroup $\mathrm{M} / \mathrm{O}$ human immunodeficiency virus type 1 recombinant isolated from a Cameroonian patient. J Virol 1999;73(9):7368-7375.

11. Nyambi $P$, Heyndrickx L, Vereecken $K$, et al.: Predominance of infection with HIV-1 circulating recombinant form CRF02_AG in major Cameroonian cities and towns. AIDS 2002;16(2):295296.

12. Ndongmo CB, Zekeng L, and Kaptue L: Increased HIV prevalence among individuals attending a sexually transmitted infection clinic in Yaounde, Cameroon. Int J STD AIDS 2003;14(3):189-192.

13. Yang C, Dash BC, Simon F, et al.: Detection of diverse variants of human immunodeficiency virus-1 groups $\mathrm{M}, \mathrm{N}$, and $\mathrm{O}$ and simian immunodeficiency viruses from chimpanzees by using generic pol and env primer pairs. J Infect Dis 2000;181(5): 1791-1795.

14. Janini LM, Tanuri A, Schechter M, et al.: Horizontal and vertical transmission of human immunodeficiency virus type 1 dual infections caused by viruses of subtypes B and C. J Infect Dis 1998; 177(1):227-231.

15. Felsenstein J: PHYLIP-phylogeny interference package (version 3.2). Cladistics 1989;5:164-166.

Address reprint requests to:
Marcia L. Kalish
Division of HIV/AIDS Prevention
Centers for Disease Control and Prevention
1600 Clifton Road, Mail Stop G45
Atlanta, Georgia 30333
E-mail: mlk3@cdc.gov

Address reprint requests to: Marcia L. Kalish or Disease Control and Prevention on Road, Mail Stop G45 E-mail: mlk3@cdc.gov 


\section{This article has been cited by:}

1. Armel Mintsa-Ndong, Melanie Caron, Jean-Christophe Plantier, Maria Makuwa, Simon Le Hello, Valerie Courgnaud , Pierre Roques, Mirdad Kazanji . 2009. High HIV Type 1 Prevalence and Wide Genetic Diversity with Dominance of Recombinant Strains But Low Level of Antiretroviral Drug-Resistance Mutations in Untreated Patients in Northeast Gabon, Central AfricaHigh HIV Type 1 Prevalence and Wide Genetic Diversity with Dominance of Recombinant Strains But Low Level of Antiretroviral Drug-Resistance Mutations in Untreated Patients in Northeast Gabon, Central Africa. AIDS Research and Human Retroviruses 25:4, 411-418. [Abstract] [PDF] [PDF Plus]

2. Hiromi Imamichi, Ousmane Koita, Djeneba Dabitao, Sounkalo Dao, Mahamadou Ibrah, Dramane Sogoba, Robin L. Dewar , Steve C. Berg, Min-Kang Jiang, Mark Parta, Janice A. Washington, Michael A. Polis , H. Clifford Lane, Anatole Tounkara . 2009. Identification and Characterization of CRF02_AG, CRF06_cpx, and CRF09_cpx Recombinant Subtypes in Mali, West AfricaIdentification and Characterization of CRF02_AG, CRF06_cpx, and CRF09_cpx Recombinant Subtypes in Mali, West Africa. AIDS Research and Human Retroviruses 25:1, 45-55. [Abstract] [PDF] [PDF Plus]

3. Catherine A Brennan, Pierre Bodelle, Ruthie Coffey, Sushil G Devare, Alan Golden, John Hackett, Barbara Harris, Vera Holzmayer, Ka-Cheung Luk, Gerald Schochetman, Priscilla Swanson, Julie Yamaguchi, Ana Vallari, Nicaise Ndembi, Charlotte Ngansop, Florence Makamche, Dora Mbanya, Lutz G Gürtler, Leopold Zekeng, Lazare Kaptué. 2009. The Prevalence of Diverse HIV-1 Strains Was Stable in Cameroonian Blood Donors From 1996 to 2004. JAIDS Journal of Acquired Immune Deficiency Syndromes 49:4, 432-439. [CrossRef]

4. Julie Yamaguchi, Samar Badreddine, Priscilla Swanson, Pierre Bodelle, Sushil G. Devare, Catherine A. Brennan . 2008. Identification of New CRF43_02G and CRF25_cpx in Saudi Arabia Based on Full Genome Sequence Analysis of Six HIV Type 1 IsolatesIdentification of New CRF43_02G and CRF25_cpx in Saudi Arabia Based on Full Genome Sequence Analysis of Six HIV Type 1 Isolates. AIDS Research and Human Retroviruses 24:10, 1327-1335. [Abstract] [PDF] [PDF Plus]

5. William M. Switzer, Albert D. Garcia, Chunfu Yang, Anthony Wright, Marcia L. Kalish, Thomas M. Folks, Walid Heneine. 2008. Coinfection with HIV-1 and Simian Foamy Virus in West Central Africans. The Journal of Infectious Diseases 197:10, 1389-1393. [CrossRef]

6. Bluma G Brenner. 2007. Resistance and viral subtypes: how important are the differences and why do they occur?. Current Opinion in HIV and AIDS 2:2, 94-102. [CrossRef] 